\title{
Disaster and mental health: The role of Sri Lankan psychiatrists
}

\author{
A Rodrigo, N Liyanage
}

DOI: http://doi.org/10.4038/sljpsyc.v8i1.8131

Disasters, whether man made or natural, have become a part of life for many in contemporaneous society. The UN report on disasters published in 2015 reported a considerable increase in the number and magnitude of disasters around the globe in the recent past (1). Sri Lanka too had witnessed this trend with unprecedented widespread floods and landslides over the last 2 years. In 2016/17 alone there were 494 deaths, while 19771 houses were destroyed due to natural disasters (2). It has been estimated that the economic damage due to flooding in 2016 was $2.43 \%$ of Sri Lanka's gross domestic production (GDP) (2). Mental health problems related to disasters are enormous and have far reaching consequences, which remain largely unaddressed (3).

The prevalence of mental morbidity in disaster affected populations varies from 8.6 to 57.3 percent (4). Most of those are acute and self-limiting, but a certain proportion of disaster victims will go on to develop more severe and enduring conditions such as posttraumatic stress disorder (PTSD), depression and substance misuse (5). Prevalence rates of PTSD, depression, anxiety were 21\%, 16\% and 30\% respectively among Sri Lankan adults and prevalence of PTSD among children was 19\% - 53.6\% following the tsunami in 2004 (6-7). A recent study done among survivors of the Aranayaka landslide in 2016 reported a $21 \%$ prevalence rate of depression (8). These rates are much higher than that of the normative population, as observed in studies conducted elsewhere, highlighting the importance of addressing mental health issues in disasters $(3,5)$. Math et al., pointed out that these problems are even more pronounced in developing countries like Sri Lanka, where the process of rehabilitation and resettlement is protracted due to various reasons (5). Therefore, Sri Lankan psychiatrists have a clear role to play in disaster situations.

The psychiatrists' role in these situations is not limited to managing the mental health morbidity of the victims after the calamity, but also in preparing populations even before these events occur, as well as helping them to return to normalcy during recovery phase. It includes treatment, education, training, negotiation, administration, collaboration, advocacy and research (5).

With the increasing frequency of disasters in the country, the Sri Lankan government has recognised the importance of planning for these at national and district levels, where authorities in the health sector play an integral role (2). Involvement of psychiatrists at both levels is very important, as they hold expertise in policy planning of disaster mental health, life skills education, training of trainers in psychological first aid and collaborating with mental health organisations in preparing for disasters. The study conducted in Aranayaka highlighted the importance of life skills as a protective factor against mental health morbidity in Sri Lankan disasters (8). There is evidence that even individuals with existing mental illness are less likely to relapse after a disaster if they are enrolled in a community assertive programme (9).

Many survivors of disasters display acute psychological stress. While robust scientific evidence for psychological first aid (PFA) is lacking, it is widely supported by expert opinion and rational conjecture for people in the immediate aftermath of disasters (10). Psychiatrists could play a pivotal role in training volunteers and community workers in the delivery of PFA, which includes engaging survivors in a non-intrusive, compassionate manner, enhancing their sense of immediate safety, calming emotionally distraught individuals, identifying immediate concerns and providing them with practical support and necessary information (10).

Psychiatrists should also play a direct role in identification and treatment of moderate to severe psychiatric illnesses among the survivors. The victims who have a previous history of psychiatric illness or substance misuse may need special attention. Individual based treatment such as trauma focused cognitive behavioural therapy and community based interventions such as structuring of daily activities, engaging children in various education methods, fostering cultural and religious rituals, and group discussions with validation of survivor's experience have been found to be useful (5). In post-war Sri Lanka, community and school based programmes to increase knowledge and skills to deal with common mental health and psychosocial issues and use of collective cultural practices were beneficial in reducing collective trauma (11). Another important role is providing care to the disaster relief workers, such as defence personnel. They too can be affected by a disaster with vicarious traumatisation, and may require screening for mental health issues (12). These treatment programmes should be conducted or coordinated via the local psychiatrist and mental health team, as continuity of care brings better results (13).

Psychiatrists should liaise with other stake holders and link survivors with necessary services during the rehabilitation process. Such rehabilitation programmes are aimed at empowering the affected community to enhance their coping abilities, with a broad public health approach. Information on the prevalence of common psychiatric disorders in post-disaster situations, cultural 
variability of response, protective factors, resilience and effectiveness of disaster preparedness are significantly sparse in Sri Lanka. Psychiatrists have a distinct role in filling this knowledge gap through research, which will in turn inform practices, such as adopting culturally acceptable rehabilitation and preventive disaster management programmes.

\section{Conflicts of interest}

None

A Rodrigo, Department of Psychiatry, University of Kelaniya, Ragama

N Liyanage, University Psychiatry Unit, Colombo South Teaching Hospital, Kalubowila

Corresponding author: A Rodrigo

Email: asirir2000@yahoo.com

http://orcid.org/0000-0003-3962-0592

\section{References}

1. United Nations Office for Disaster Risk Reduction (UNISDR). The global assessment report on disaster risk reduction. Geneva: UNISDR; 2015.

2. Disaster Management Centre [homepage on the Internet]. Situation report on disasters, Colombo c2017. Available at: http:// www.dmc.gov.lk/ (accessed June 2017).

3. Ursano RJ, Cerise FP, Demartino R, Reissman DB, Shear MK.The impact of disasters and their aftermath on mental health. Prim Care Companion J Clin Psychiatry 2006; 8(1): 4-11.
4. Udomratn P. Mental health and the psychosocial consequences of natural disasters in Asia. Int Rev Psychiatry. 2008; 20: 441-4.

5. Math SB, Nirmala MC, Moirangthem S, Kumar NC. Disaster Management: Mental Health Perspective. Indian J Psychol Med. 2015; 37(3): 261-71.

6. Neuner F, Schauer E, Catani C, Ruf M, Elbert T. Posttsunami stress: a study of posttraumatic stress disorder in children living in three severely affected regions in Sri Lanka. J Trauma Stress. 2006; 19(3): 339-47.

7. Gunaratne CG, Kremer PJ, Lewis AJ, Clarke V. Trauma symptoms in children after the tsunami. Sri Lanka Journal of Child Health, 2013; 42: 192-99.

8. Rowel WWJSM, Hewawitharana UH, Kumarasinghe WGGB, Askath MSA, Rodrigo A. Determinants of resilience in a Sri Lankan population after a natural disaster. 14th Annual academic sessions of Sri Lanka College of Psychiatrists; 2017 Apr 27-30; Colombo.

9. Person C, Fuller EJ. Disaster care for persons with psychiatric disabilities: recommendations for policy change. J Disabil Policy Stud 2007: 17(4): 238-48.

10. Fox JH, Burkle FM Jr, Bass J, Pia FA, Epstein JL, Markenson D. The effectiveness of psychological first aid as a disaster intervention tool: research analysis of peerreviewed literature from 1990-2010. Disaster Med Public Health Prep 2012; 6(3): 247-52.

11. Somasundaram D, Sivayokan S. Rebuilding community resilience in a post-war context: developing insight and recommendations - a qualitative study in Northern Sri Lanka. Int J Ment Health Syst. 2013; 7(1): 3.

12. McCann IL, Pearlman LA. Vicarious traumatization: A framework the psychological effects of working with victims. J Trauma Stress. 1990; 3: 131-49.

13. Adair CE, McDougall GM, Mitton CR, Joyce AS, Wild TC, et al. Continuity of care and health outcomes among persons with severe mental illness. Psychiatr Serv. 2005; 56(9): 1061-9. 